\title{
Inovação na comunicação da memória institucional: o caso dos 100 anos da CPFL Energia
}

Innovation in institutional memory communication: the case of the 100 years of CPFL Energia

Innovación en la comunicación de la memoria institucional: el caso de los 100 años de la CPFL Energia

João de Deus Dias Neto

- Mestre em Comunicação pela Universidade Municipal de São Caetano do Sul (USCS)

- Especialista em Propaganda pela Escola Superior de Propaganda e Marketing (ESPM)

- Graduado em Administração pela Faculdade de Ciências Administrativas e Contábeis Paulo Eiró

- Membro do Grupo de Estudos de Novas Narrativas (Genn) da Escola de Comunicações e Artes da Universidade de São Paulo (ECA-USP)

- Pesquisador do Programa de Pós-Graduação em Comunicação da USCS

- Professor da Faculdade de Tecnologia de São Paulo (Fatec) e do Serviço Nacional de Aprendizagem Comercial (Senac)

- E-mail: deus.neto@uol.com.br

\section{Priscila Ferreira Perazzo}

- Doutora, mestre e bacharel em História Social pela Faculdade de Filosofia, Letras e Ciências Humanas da Universidade de São Paulo (FFLCH-USP)

- Docente e coordenadora do Programa de Pós-Graduação em Comunicação da Universidade Municipal de São Caetano do Sul (USCS)

- Coordenadora do Laboratório de Hipermídias da USCS

- Lider do Grupo Memórias do ABC, da USCS

- E-mail: prisperazzo2@gmail.com 


\section{Resumo}

Esta pesquisa identificou e descreveu a inovação nas ações comunicacionais de memória do "Projeto CPFL 100 Anos". Partiu da análise do conteúdo das peças do projeto. Com linguagens plurais, os produtos comunicacionais apresentaram ações e tecnologias diferenciadas: eventos institucionais, convencionais, culturais, educacionais, produtos editoriais, eventos musicais e esportivos, ações relacionadas a espaço físico e virtual para preservação da memória e sete ações e eventos especiais. 0 projeto teve relativa produção de novos formatos, novos processos e ações comunicacionais inovadoras.

\section{PALAVRAS-CHAVE: COMUNICAÇÃO •INOVAÇÃO • MEMÓRIA INSTITUCIONAL.}

\section{Abstract}

This research has identified and described the innovation in memory communicational actions of the CPFL 100 Years Project. It started from an analysis of the content of the parts of the project. In a plural language, the communication products presented actions and differentiated technologies: institutional, conventional, cultural, educational events, editorial products, musical and sporting events, actions related to the physical and virtual environment for preservation of the memory, and seven special actions and events. The project had relative production of new formats, new processes and innovative communicational actions.

\section{KEYWORDS: COMMUNICATION •INNOVATION •INSTITUTIONAL MEMORY}

\section{Resumen}

Esta investigación identificó y describió la innovación en las acciones de comunicación de memoria del "Proyecto CPFL 100 años". La investigación ha sido iniciada a partir del análisis de contenido de las piezas del proyecto. Con lenguajes plurales, los productos comunicacionales presentan acciones y tecnologías diferenciadas: eventos institucionales, convencionales, culturales, educacionales, productos editoriales, eventos musicales y deportivos, acciones relacionadas con el espacio físico y virtual para la preservación de la memoria y siete acciones y eventos especiales. El proyecto tuvo relativa producción de nuevos formatos, nuevos procesos y acciones comunicacionales innovadoras. 
sta pesquisa objetivou identificar e descrever os tipos de inovação nas ações da comunicação de memória do "Projeto CPFL 100 Anos", a partir de uma matriz de categorização de inovação em comunicação de Regina Rossetti (2013). Para tal, optou-se pela análise de conteúdo de sete peças, consideradas especiais, dentre as trinta e quatro ações comunicativas do projeto.

A Companhia Paulista de Força e Luz (CPFL), mais conhecida como CPFL Energia, completou, em 2012, cem anos de atuação no setor elétrico. Fundada em 16 de novembro de 1912, com sede em Campinas (SP), ela opera nos segmentos de geração e distribuição de energia, além de telecomunicações.

Já em 2011, ela deu início ao "Projeto CPFL 100 anos", amplo conjunto de ações comunicacionais, visando ao reforço da imagem corporativa. A complexidade desse projeto de comunicação institucional, premiado na categoria Responsabilidade Histórica e Memória Empresarial de 2013, da Associação Brasileira de Comunicação Empresarial (Aberje), motivou sua exploração no sentido de identificação de quais tipos de inovação estão presentes nessas ações empreendidas para marcar o centenário da empresa.

\section{CATEGORIAS DE INOVAÇÃO EM COMUNICAÇÃO}

0 estudo desenvolveu-se por meio de pesquisa qualitativa em nível exploratório, com aplicação de análise de conteúdo. A coleta de dados se deu pela busca por produtos de comunicação e os procedimentos visaram identificar e descrever ações da comunicação do "Projeto CPFL 100 anos" e posterior identificação dos tipos de inovação em que essas ações se configuravam.

Elegeu-se o modelo de Rossetti (2013), denominado "Categorias de inovação para os estudos em comunicação", que apresenta indicadores que classificam inovação em oito categorias: substancial, qualitativa, quantitativa, relativa, espacial, temporal, ativa e passiva. A pesquisadora fez abordagem da inovação como fenômeno social e correlacionou comunicação e filosofia, articulando-as para o desenvolvimento de seus pressupostos, partindo da concepção de Aristóteles sobre inovação e sua classificação, para mapear e elencar modos de inovação no campo da comunicação (Rossetti, 2013).

Durante o processo de categorização de elementos de um conteúdo comunicacional gerado pelo "Projeto CPFL 100 anos", foi realizada uma operação de classificação de elementos constitutivos de um conjunto, que foram separados por "diferenciação e, em seguida, por reagrupamento segundo o gênero (analogia), com os critérios previamente definidos" (Bardin, 2011, p. 147). Os procedimentos metodológicos classificaram as ações realizadas pela CPFL em categorias de inovação, adotando-se os títulos apresentados por Rossetti (2013), fazendo-se agrupamentos em razão de características comuns nos elementos analisados (peças de comunicação).

Quanto à categoria substancial, "a geração é uma ação decorrente da criação e da invenção, pois estes dois procedimentos fazem surgir o novo", remetendo à natureza das coisas (Rossetti, 2013, p. 67).

No tocante à categoria qualitativa, atos que trazem movimento, mutação, transmutação, reformulação, deformação, metamorfose ou transfiguração podem causar mudança na forma (transformação), mudança no modo (modificação) ou alteração na ação de comunicação (Rossetti, 2013).

A categoria quantitativa indica multiplicabilidade nas ações de comunicação. Refere-se à variabilidade, multiplicação e massificação dos atos comunicativos. 
A categoria de inovação relativa abrange situações em que houve diversificação ou diferenciação em produtos comunicacionais. Há que se observar sinais que exprimam ato ou evento "diverso, diferenciado, diferente, dessemelhante, incomum ou de alteridade" na comunicação (Rossetti, 2013).

A categoria espacial fundamenta-se nos processos em que houve salto, tradução e transposição nos produtos gerados pela comunicação. "Salto é a passagem brusca e sem mediação de um estado para outro" (Rossetti, 2013, p. 70). Para a autora, a instauração do novo, pelo rompimento com o velho, traz comunicação inovadora. Sobre a tradutibilidade, essa não existe pura na tradução, sendo a tradução sempre nova em relação ao original. A alteração na colocação ou ordem de determinados termos e/ou sentidos, para a comunicação, é elemento de inovação, pois há transição de um sentido a outro, de uma formatação de gênero a outra. A transposição como variante de inovação "pode favorecer o surgimento de novas qualidades e propriedades que não existiam no gênero de partida e que são trazidas à luz no gênero de chegada" (Rossetti, 2013, p. 70). Transposições são pensadas como arranjos ou adaptações de gêneros, de mídias e de sentidos que "implicam mudanças nas linguagens e, ao mesmo tempo, promovem inovações de formato, sintaxe ou conteúdo" (Rossetti, 2013, p. 70).

A categoria temporal é alicerçada em dois formatos de inovação: ruptura e evolução. Nos processos em que se verifica a existência de cenários de desenvolvimento, aprimoramento, aperfeiçoamento, progresso, incremento ou corte (interrupção), tem-se inovação temporal. A evolução apresenta-se a partir de geração, aumento, continuidade e acréscimo com desenvolvimento progressivo. Em relação à ruptura, a autora a define como um "corte repentino com o estado anterior e 0 surgimento descontínuo de um novo estado" (Rossetti, 2013, p. 70). Para ela, a ruptura dá-se em duas dimensões. A primeira é epistemológica, pois vem da negação daquilo que é velho em termos de comunicação, fazendo surgir uma nova teoria. A segunda dimensão da ruptura é a revolução científica, tal qual acontece em uma mudança descontínua de paradigma, quando, então, a inovação pode surgir abruptamente e em situação de descontinuidade. Essa categoria elege o "novo no tempo: o primeiro, o primordial e o matricial" (Rossetti, 2013, p.70).

O modelo de Rossetti (2013) também considera o sujeito e o objeto da comunicação, analisando situações de ação (sujeito) e de paixão (objeto).

Assim, a penúltima categoria tem vínculo com o sujeito, o agente inovador e a ação das pessoas enquanto propulsoras da inovação. A autora fala na categoria ativa, quando o sujeito é inovador ou, em outras palavras, quando existe uma ação comunicacional inovadora por parte do sujeito. "No campo da comunicação, este sujeito inovador diz respeito aos agentes envolvidos no processo de comunicação (como o emissor e o receptor) e diz respeito também às novas visões teóricas da comunicação" (Rosseti, 2013, p. 70).

Por fim, categoria passiva é aquela em que o objeto inovado é a referência de análise. Nesse critério, há a paixão, no sentido daquele que se submete, aquele que sofre a ação que gerou nele a inovação, pois "é o efeito da inovação que gera um produto inovado. A inovação está no objeto como seu fim. É o novo que surge como resultado do processo de inovação" (Rossetti, 2013, p. 70).

Explicitadas as categorias de inovação escolhidas para categorização das ações, dos eventos e das peças extraídas dos produtos comunicacionais do "Projeto CPFL 100 anos", são delineados, a seguir, os procedimentos de como a amostra foi obtida e tratada. 


\section{ANO 13 • NÚMERO 24 • 1ํSM. 2016 • ORGANICOM

\section{QUESTÕES METODOLÓGICAS}

A pesquisa iniciou-se com o levantamento do Prêmio Aberje, da Associação Brasileira de Comunicação Organizacional (Aberje), de 2004 a 2015, na categoria "responsabilidade histórica e memória empresarial". 0 "Projeto CPFL 100 Anos" destacou-se dos demais pela quantidade de ações e sinais de inovação em comunicação de memória institucional. A pluralidade de linguagens é notória, quando são elencados os produtos gerados no período de comemoração, que se estendeu ao longo de 2012, permanecendo até meados de 2013. A coleta de dados sobre essas produções deu forma ao corpus da pesquisa, que identificou várias ações e tecnologias diferenciadas. Das mais simples, como um encontro entre 0 presidente da empresa num café da manhã, aos recursos tecnológicos de ponta, envolvendo tecnologias da informação e da comunicação, que permitiam interatividade com públicos diversos.

A amostra apresenta-se como um conjunto das ações comunicativas em nove formatações específicas, categorizadas após análise de diversos projetos de memória institucional premiados pela Aberje, a saber: eventos institucionais; eventos convencionais; eventos culturais e educacionais, produtos editoriais (livros, vídeos e revistas); eventos musicais; eventos esportivos; espaço físico; espaço virtual; e eventos especiais. As ações de comunicação e memória do "Projeto CPFL 100 anos", desenvolvidas, produzidas e disseminadas, num total de trinta e quatro produtos, foram classificadas dentro dos formatos elencados na Tabela 1, a seguir.

Tabela 1 - Produtos do "Projeto CPFL 100 anos"

\begin{tabular}{|c|c|c|}
\hline $\begin{array}{l}\text { Ações de comunicação e memória do } \\
\text { "Projeto CPFL } 100 \text { anos" }\end{array}$ & \multirow[t]{2}{*}{ Target } & \multirow[t]{2}{*}{ Período } \\
\hline a. Eventos institucionais & & \\
\hline 01 Lançamento da marca comemorativa e do programa. & 7.500 funcionários & $17 / 11 / 2011$ \\
\hline 02 Relógio eletrônico - contagem regressiva - 100 dias para o centenário. & \multirow{2}{*}{8.200 funcionários } & \multirow{2}{*}{$08 / 08 / 2012$} \\
\hline 03 Cápsula do tempo CPFL (abertura) - enterrada desde 1.992. & & \\
\hline 04 Café da manhã com colaboradores e premiação de concursos. & 8.200 funcionários & 14/11/2012 \\
\hline 05 Sessão solene na Assembleia Legislativa do Estado de São Paulo. & $\begin{array}{c}200 \\
\text { pessoas }\end{array}$ & $23 / 11 / 2012$ \\
\hline $\begin{array}{l}06 \text { Inauguração da primeira usina solar do Estado de São Paulo: usina } \\
\text { Solar Tanquinho }\end{array}$ & 500 pessoas & $27 / 11 / 2012$ \\
\hline 07 Lançamento oficial de selo e carimbo comemorativo: 100 Anos CPFL. & $\begin{array}{l}\text { principais } \\
\text { stakeholders }\end{array}$ & 2012 \\
\hline 08 Encontro de ex-colaboradores: comunidade "Colegas da CPFL" - Facebook. & 85 ex-funcionários & $11 / 12 / 2012$ \\
\hline $\begin{array}{l}09 \text { Comunicação interna especial: sede e regionais, hotsite "CPFL } 100 \\
\text { Anos" e gincana "Juntos vamos construir a história do nosso centenário". }\end{array}$ & $\begin{array}{l}\text { 8.200 funcionários } \\
+ \text { visitantes }\end{array}$ & 2012 \\
\hline $\begin{array}{l}10 \text { Kit "CPFL: } 100 \text { anos gerando histórias" - brinde de final de ano. } \\
\text { Conteúdo: Livro "100 anos de história e energia", Documentário } \\
\text { "100 anos luz" e Livro de arte "100 anos de história e energia". }\end{array}$ & $\begin{array}{l}\text { principais } \\
\text { stakeholders }\end{array}$ & 2013 \\
\hline
\end{tabular}




\begin{tabular}{|c|c|c|}
\hline b. Eventos convencionais de comunicação & Target & Período \\
\hline $\begin{array}{l}11 \text { Campanha externa especial de } 100 \text { anos - anúncios (físico e } \\
\text { eletrônico): verso da conta de energia elétrica. }\end{array}$ & $\begin{array}{l}7 \text { milhões } \\
\text { de clientes }\end{array}$ & 2012 \\
\hline $\begin{array}{l}12 \text { Comunicação digital (mídias sociais) - eventos CPFL } 100 \text { anos: } \\
\text { Facebook; Twitter e Instagram. }\end{array}$ & $\begin{array}{c}\text { 1,2 milhão de } \\
\text { potenciais } \\
\text { usuários }\end{array}$ & 2012 \\
\hline $\begin{array}{l}13 \text { Mídia espontânea: book imprensa (eletrônico). Folha de S.Paulo, O } \\
\text { Estado de S. Paulo, revistas impressas, digitais, emissoras: rádio e tv. }\end{array}$ & - & 2012 \\
\hline c. Eventos culturais e educacionais & Target & Período \\
\hline $\begin{array}{l}14 \text { Domingo Energia: encontro das famílias dos funcionários / } \\
\text { brincadeiras / caminhão da CPFL em escolas, exposições e sorteios. }\end{array}$ & 1.500 pessoas & $02 / 12 / 2012$ \\
\hline $\begin{array}{l}15 \text { Programação CPFL Cultura: "Invenção do contemporâneo" e } \\
\text { "Café filosófico" com o tema dos } 100 \text { anos CPFL. }\end{array}$ & $\begin{array}{c}8.300 \text { pessoas } \\
\text { nos eventos e } \\
14.600 \text { via internet }\end{array}$ & 2012 \\
\hline d. Produtos editoriais: & Target & Período \\
\hline 16 Livro de arte "100 anos de história e energia" - físico e eletrônico. & - & 2012 \\
\hline 17 Livro de texto "100 anos de história e energia". & - & 2012 \\
\hline 18 Vídeos especiais de 100 anos: suporte aos eventos da CPFL. & - & 2013 \\
\hline 19 DVD "100 anos de luz e som": 2500 cópias. & - & 2013 \\
\hline 20 Livro documentário "100 anos luz" - físico e eletrônico -1500 cópias. & - & 2013 \\
\hline 21 Patrocínio de obras literárias: Pensar a filosofia e Pensar a cultura. & - & 2013 \\
\hline e. Eventos musicais & Target & Período \\
\hline $\begin{array}{l}22 \text { Show comemorativo "100 anos de luz e som": espetáculo de } \\
\text { música brasileira realizado em São Paulo, no teatro Alfa. }\end{array}$ & 1.020 pessoas & $20 / 11 / 2012$ \\
\hline f. Eventos esportivos & Target & Período \\
\hline $\begin{array}{l}23 \text { Programa de Esportes CPFL Energia: circuito Energia } \\
\text { (10 corridas) e patrocínio de atletas olímpicos. }\end{array}$ & 8.000 pessoas & $\begin{array}{c}\text { abr/2012 a } \\
\text { nov/2012 }\end{array}$ \\
\hline g. Espaço físico para preservação da memória & Target & Período \\
\hline 24 Nova fachada na sede em Campinas. & \multirow{3}{*}{-} & \multirow{3}{*}{2012} \\
\hline 25 Criação do Hall da Energia. & & \\
\hline 26 Recuperação e organização do acervo histórico. & & \\
\hline h. Espaço virtual para preservação da memória: & Target & Período \\
\hline 27 Site "Memória viva": http://memoriaviva.cpfl.com.br/. & $\begin{array}{l}21.000 \\
\text { visitas/2013 }\end{array}$ & 2012 \\
\hline
\end{tabular}




\begin{tabular}{|c|c|c|}
\hline i. Ações/Eventos especiais & Target & Período \\
\hline 28 Apresentações da Esquadrilha da Fumaça - CPFL 100 Anos. & 8.200 & $\begin{array}{r}\text { jul/2012 a } \\
\text { nov/2012 }\end{array}$ \\
\hline 29 Night run CPFL 100 Anos: corrida noturna. & 2.500 atletas & $24 / 11 / 2012$ \\
\hline $\begin{array}{l}30 \text { Exposição itinerante "100 anos de história e energia": mostra } \\
\text { interativa com exposição em várias cidades: Campinas, Santos, } \\
\text { Sorocaba, Ribeirão Preto, Bauru, Caxias do Sul e Porto Alegre. }\end{array}$ & $\begin{array}{c}\text { Campinas: } \\
3.000 \text { pessoas } \\
\text { Santos:1.500 } \\
\text { pessoas } \\
\end{array}$ & $\begin{array}{l}\mathrm{nov} / 2012 \text { a } \\
\mathrm{mai} / 2013\end{array}$ \\
\hline $\begin{array}{l}31 \text { Exposição Especial 1: } 100 \text { anos de arte paulista } \\
\text { - Coleção da Pinacoteca do Estado. }\end{array}$ & \multirow{4}{*}{35.000 pessoas } & \multirow{4}{*}{$\begin{array}{l}\mathrm{fev} / 2012 \mathrm{a} \\
\mathrm{mai} / 2013\end{array}$} \\
\hline 32 Exposição Especial 2 - Gênese e celebração. & & \\
\hline 33 Exposição Especial 3 - Memória e altar. & & \\
\hline 34 Exposição Especial 4 - Zoom latino-americano. & & \\
\hline
\end{tabular}

Fontes: Prêmio Aberje e Revista CPFL - "100 anos gerando histórias" (edição especial - 2012).

Em seguida, elencaram-se os produtos comunicacionais caracterizados como ações/eventos especiais, submetidos à análise de conteúdo, com a intenção de enquadramento em categorias de inovação, conforme previsto na metodologia da pesquisa. A amostra configurou-se em sete ações (peças de comunicação) consideradas inovadoras, assim selecionadas:

1. Apresentações da Esquadrilha da Fumaça - CPFL 100 anos;

2. Night runCPFL 100 anos: corrida noturna;

3. Exposição itinerante "100 anos de história e energia": mostra interativa com exposição em Campinas, Santos, Sorocaba, Ribeirão Preto, Bauru, Caxias do Sul e Porto Alegre;

4. Exposição especial 1: 100 anos de arte paulista - Coleção Pinacoteca do Estado;

5. Exposição especial 2: Gênese e celebração;

6. Exposição especial 3: Memória e altar;

7. Exposição especial 4: Zoom latino-americano.

\section{Análise dos prêmios Aberje}

A análise das empresas laureadas com o Prêmio Aberje objetivou detectar elementos de inovação, conforme preconiza Rossetti (2013). Sintetizando-se os doze anos de premiação, incluindo-se os produtos do "Projeto CPFL 100 anos", observa-se a predominância do desenvolvimento de ações comunicacionais voltadas para centros de memória e museus (espaços físicos para preservação da memória), presentes em 11 projetos. Com a mesma quantidade de ações, constatou-se a existência de 11 iniciativas para a geração de produtos editoriais, enquanto 8 empresas optaram por ações e eventos ligados à cultura e educação - exposições, visitas escolares e entretenimento. A utilização das tecnologias de informação e comunicação, especialmente sites específicos sobre memória e história, apareceram em 6 empresas. Constatou-se que 3 organizações 
optaram por eventos convencionais de comunicação - anúncios, mídias sociais e ações de comunicação tradicional-enquanto 3 empresas promoveram eventos musicais. Os mais tradicionais como café com a presidência e jornal institucional fizeram parte das ações de 2 empresas. Apenas a CPFL incluiu em seu projeto eventos esportivos: corridas, torneios e campeonatos.

Excluindo-se a CPFL, houve 12 organizações premiadas (em 2010 foram dois vencedores), com 45 produtos de comunicação de memória institucional ao todo, obtendo-se uma média de 3,7 produtos (ações, eventos e produtos) para cada participante vencedor da premiação. A CPFL desenvolveu 34 ações, diferenciando-se das demais ao desenvolver extensa gama de produtos para registrar os cem anos de sua fundação. Mas, apenas 7 peças de comunicação da CPFL configuraram-se como ações inovadoras, sobre as quais se faz, no próximo tópico do texto, a aplicação das categorias de Rossetti (2013) a fim de identificar os tipos de inovação e descrevê-los.

Quanto à análise dos produtos comunicacionais vencedores do Prêmio Aberje, o que se vê éuma tensão entre tradição e inovação na produção da memória institucional expressa nos produtos comunicacionais. Das ações premiadas, 11 desenvolveram centros de memória e museus, bem como produtos editoriais. Essas ações podem ser consideradas ações tradicionais da comunicação da memória institucional. Todavia, isso não significa necessariamente a ausência de inovação. A implantação de museus e centros de memória das empresas, apesar de serem ações recorrentes (D'Almeida, 2014), podem apresentar novas formas de concepção, organização e expressão, pois trata-se de um sistema de signos que se estende e se sofistica, englobando

as dimensões materiais (arquitetura de empresa), imateriais (websites, presença nas redes sociais), racionais e emocionais. 0 imperativo comunicacional consiste em buscar uma presença multiforme e reconhecível, no espaço físico, no espaço midiático e no espaço mental das sociedades e dos indivíduos (D'Almeida, 2014, p. 152).

Considera-se assim, que as ações inovadoras de comunicação em memória organizacional buscamatenderao pressuposto de que "a modernidade se caracteriza pela quebra do fio da tradição" (D'Almeida, 2014, p. 152). Aquelas que conseguem fazer a conjunção entre tradição e inovação podem ter mais possibilidades de interagir com diversos públicos. No caso do "Projeto CPFL 100 anos", vimos que,

diante de uma responsabilidade tão grande, de celebrar a tradição com visão de futuro e com o cenário especialmente delicado (...), nada melhor do que contar a memória da empresa a partir das histórias vividas ali dentro, pelos colaboradores. Documentários, exposições, acervos, exposições e até um hall com experiências interativas multimídia integraram dezenas de eventos (Nassar, 2014, p. 145).

Tomando-se em conjunto as ações de memória institucional, vê-se que a inovação pode se dar por novas maneiras de articular a comunicação. Tendo sido escolhido o "Projeto CPFL 100 anos" como objeto de análise dessa pesquisa, foi possível perceber como se dá a tensão entre tradição e inovação e como os produtos comunicacionais podem ser elaborados e reelaborados a partir de tipos próprios de inovação, com base nas categorias de Rossetti (2013).

\section{Inovação nas ações de comunicação do "Projeto CPFL 100 anos "}

Com linguagens plurais, os produtos gerados apresentaram ações e tecnologias diferenciadas: eventos institucionais, convencionais, culturais e educacionais, musicais, esportivos, produtos editoriais, espaço físico e virtual para preservação da memória e sete ações e eventos especiais. A CPFL atuou com relativo desenvolvimento e produção de novos formatos, processos e ações comunicacionais. As análises indicam alguns importantes vetores de inovação. 0 Quadro 1 destaca as incidências das categorias de inovação nos processos considerados especiais. 
Quadro 1 - Predominâncias de categorias de inovação

\begin{tabular}{|c|c|c|c|}
\hline Categoria & Incidências & Característica & Frequência \\
\hline \multirow{3}{*}{ 1. Substancial } & \multirow{3}{*}{07} & Criação absoluta & 01 \\
\hline & & Criação relativa & 06 \\
\hline & & Invenção & 00 \\
\hline \multirow{3}{*}{ 2. Qualitativa } & \multirow{3}{*}{07} & Alteração & 02 \\
\hline & & Transformação & 06 \\
\hline & & Modificação & 07 \\
\hline \multirow{2}{*}{ 3. Quantitativa } & \multirow{2}{*}{07} & Quantidade & 02 \\
\hline & & Massificação & 05 \\
\hline \multirow{2}{*}{ 4. Relativa } & \multirow{2}{*}{07} & Diferenciação & 07 \\
\hline & & Diversificação & 00 \\
\hline \multirow{3}{*}{ 5. Espacial } & \multirow{3}{*}{07} & Salto & 07 \\
\hline & & Transposição & 07 \\
\hline & & Tradução & 00 \\
\hline \multirow{2}{*}{ 6. Temporal } & \multirow{2}{*}{07} & Evolução & 07 \\
\hline & & Ruptura & 07 \\
\hline 7. Ativa & 07 & Ação do sujeito & 07 \\
\hline \multirow{2}{*}{ 8. Passiva } & \multirow{2}{*}{02} & Produto inovado & 01 \\
\hline & & Produto novo & 01 \\
\hline
\end{tabular}

Fonte: Dados da pesquisa dos autores.

A análise do Quadro 1 revela que na categoria passiva, correspondente a produtos novos ou inovados, não houve a totalidade de incidências. 0 Quadro 2, a seguir, demonstra as sete produções de comunicação selecionadas no "Projeto CPFL 100 anos".

Quadro 2 - Análise categorial: ações de comunicação (produtos ou processos / atos ou efeitos) geradas no "Projeto CPFL 100 anos"RESULTADOS

Evento / Produto

1. Apresentações da Esquadrilha da Fumaça - CPFL 100 Anos

2. Exposição itinerante "100 anos de história e energia": Campinas, Santos, Sorocaba, Ribeirão Preto, Bauru, Caxias do Sul e Porto Alegre.

3. Exposição Especial 1: 100 anos de arte paulista - Coleção da Pinacoteca do Estado

4. Night run CPFL 100 Anos: corrida noturna

5. Exposição Especial 2: Gênese e celebração

6. Exposição Especial 3: Memória e altar

7. Exposição Especial 4: Zoom latino-americano 


\begin{tabular}{|c|c|c|c|c|c|c|c|c|}
\hline \multirow{2}{*}{ AÇÃO } & \multicolumn{8}{|c|}{ CATEGORIA } \\
\hline & SUBSTANCIAL & QUALITATIVA & QUANTITATIVA & RELATIVA & ESPACIAL & TEMPORAL & ATIVA & PASSIVA \\
\hline 1 & $\begin{array}{l}\text { Criação relativa: } \\
\text { Esquadrilha } \\
\text { da Fumaça. }\end{array}$ & $\begin{array}{l}\text { Alteração, } \\
\text { transformação e } \\
\text { modificação na } \\
\text { comunicação. }\end{array}$ & $\begin{array}{l}\text { Quantidade de } \\
\text { apresentações. }\end{array}$ & $\begin{array}{l}\text { Diferenciação } \\
\text { na forma de } \\
\text { comunicação. }\end{array}$ & $\begin{array}{l}\text { Salto: passagem } \\
\text { brusca na } \\
\text { comunicação } \\
\text { institucional e } \\
\text { transposição } \\
\text { de gênero. }\end{array}$ & $\begin{array}{l}\text { Evolução: } \\
\text { mudança no } \\
\text { sentido do } \\
\text { acréscimo na } \\
\text { formatação } \\
\text { e ruptura } \\
\text { pelo corte } \\
\text { repentino na } \\
\text { forma de se } \\
\text { comunicar. }\end{array}$ & $\begin{array}{l}\text { Mudança } \\
\text { no } \\
\text { processo: } \\
\text { ação do } \\
\text { sujeito. }\end{array}$ & $\begin{array}{l}\text { Produto novo: } \\
\text { comunicação } \\
\text { pela } \\
\text { apresentação } \\
\text { dos aviões. }\end{array}$ \\
\hline 2 & $\begin{array}{l}\text { Criação relativa: } \\
\text { Exposição } \\
\text { Itinerante "100 } \\
\text { anos de história } \\
\text { e energia" }\end{array}$ & $\begin{array}{l}\text { Mudança } \\
\text { na forma } \\
\text { (transformação) } \\
\text { de se comunicar } \\
\text { e no modo } \\
\text { (modificação) } \\
\text { - recursos de } \\
\text { multimídia. }\end{array}$ & $\begin{array}{l}\text { Massificação } \\
\text { pela itinerância. }\end{array}$ & $\begin{array}{l}\text { Diferenciação } \\
\text { na forma de } \\
\text { comunicação. }\end{array}$ & $\begin{array}{l}\text { Salto: passagem } \\
\text { brusca na } \\
\text { comunicação } \\
\text { institucional e } \\
\text { transposição } \\
\text { de gênero. }\end{array}$ & $\begin{array}{l}\text { Evolução com } \\
\text { mudança no } \\
\text { sentido do } \\
\text { acréscimo na } \\
\text { formatação } \\
\text { e ruptura } \\
\text { pelo corte } \\
\text { repentino na } \\
\text { forma de se } \\
\text { comunicar } \\
\text { (exposição } \\
\text { itinerante). }\end{array}$ & $\begin{array}{l}\text { Mudança } \\
\text { no } \\
\text { processo: } \\
\text { ação do } \\
\text { sujeito. }\end{array}$ & --- \\
\hline 3 & $\begin{array}{l}\text { Criação absoluta: } \\
\text { Exposição } 1 \text { - } 100 \\
\text { anos de Arte } \\
\text { Paulista - Coleção } \\
\text { Pinacoteca } \\
\text { do Estado } \\
\text { (itinerante) }\end{array}$ & $\begin{array}{l}\text { Mudança } \\
\text { na forma } \\
\text { (transformação) } \\
\text { de se comunicar } \\
\text { e no modo } \\
\text { (modificação): } \\
\text { exposição de } \\
\text { arte itinerante. }\end{array}$ & $\begin{array}{l}\text { Massificação } \\
\text { pela quantidade } \\
\text { de cidades que } \\
\text { receberam a } \\
\text { exposição. }\end{array}$ & $\begin{array}{l}\text { Diferenciação } \\
\text { na forma de } \\
\text { comunicação. }\end{array}$ & $\begin{array}{l}\text { Salto: passagem } \\
\text { brusca na } \\
\text { comunicação } \\
\text { e transposição } \\
\text { de gênero. }\end{array}$ & $\begin{array}{l}\text { Evolução com } \\
\text { mudança no } \\
\text { sentido do } \\
\text { acréscimo na } \\
\text { formatação } \\
\text { e ruptura } \\
\text { pelo corte } \\
\text { repentino na } \\
\text { forma de se } \\
\text { comunicar } \\
\text { (exposição } \\
\text { itinerante). }\end{array}$ & $\begin{array}{l}\text { Mudança } \\
\text { no } \\
\text { processo: } \\
\text { ação do } \\
\text { sujeito. }\end{array}$ & --- \\
\hline 4 & $\begin{array}{l}\text { Criação relativa: } \\
\text { Corrida noturna }\end{array}$ & $\begin{array}{l}\text { Ação alterada } \\
\text { e modificada. }\end{array}$ & $\begin{array}{l}\text { Quantidade: } \\
\text { várias outras } \\
\text { corridas foram } \\
\text { realizadas. }\end{array}$ & $\begin{array}{l}\text { Diferenciação } \\
\text { na forma. }\end{array}$ & $\begin{array}{l}\text { Salto: ruptura } \\
\text { brusca e } \\
\text { transposição } \\
\text { no gênero } \\
\text { comunicacional. }\end{array}$ & $\begin{array}{l}\text { Evolução com } \\
\text { mudança no } \\
\text { sentido do } \\
\text { acréscimo na } \\
\text { formatação } \\
\text { e ruptura. }\end{array}$ & $\begin{array}{l}\text { Mudança } \\
\text { no } \\
\text { processo: } \\
\text { ação do } \\
\text { sujeito. }\end{array}$ & $\begin{array}{l}\text { Produto } \\
\text { inovado: } \\
\text { corrida } \\
\text { noturna. }\end{array}$ \\
\hline 5 & $\begin{array}{l}\text { Criação relativa: } \\
\text { Exposição } 2 \text { - } \\
\text { Gênese e } \\
\text { celebração } \\
\text { (itinerante) }\end{array}$ & $\begin{array}{l}\text { Mudança } \\
\text { na forma } \\
\text { (transformação) } \\
\text { de se comunicar } \\
\text { e no modo } \\
\text { (modificação): } \\
\text { exposição de } \\
\text { arte itinerante. }\end{array}$ & $\begin{array}{l}\text { Massificação } \\
\text { pela quantidade } \\
\text { de cidades que } \\
\text { receberam a } \\
\text { exposição. }\end{array}$ & $\begin{array}{l}\text { Diferenciação } \\
\text { na forma de } \\
\text { comunicação. }\end{array}$ & $\begin{array}{l}\text { Salto: passagem } \\
\text { brusca na } \\
\text { comunicação } \\
\text { e transposição } \\
\text { de gênero. }\end{array}$ & $\begin{array}{l}\text { Evolução com } \\
\text { mudança no } \\
\text { sentido do } \\
\text { acréscimo na } \\
\text { formatação } \\
\text { e ruptura } \\
\text { pelo corte } \\
\text { repentino na } \\
\text { forma de se } \\
\text { comunicar } \\
\text { (exposição } \\
\text { itinerante). }\end{array}$ & $\begin{array}{l}\text { Mudança } \\
\text { no } \\
\text { processo: } \\
\text { ação do } \\
\text { sujeito. }\end{array}$ & --- \\
\hline
\end{tabular}




\begin{tabular}{|c|c|c|c|c|c|c|c|c|}
\hline \multirow{2}{*}{ AÇÃO } & \multicolumn{8}{|c|}{ CATEGORIA } \\
\hline & SUBSTANCIAL & QUALITATIVA & QUANTITATIVA & RELATIVA & ESPACIAL & TEMPORAL & ATIVA & PASSIVA \\
\hline 6 & $\begin{array}{l}\text { Criação relativa: } \\
\text { Exposição } 3 \text { - } \\
\text { Memória e altar } \\
\text { (itinerante) }\end{array}$ & $\begin{array}{l}\text { Mudança } \\
\text { na forma } \\
\text { (transformação) } \\
\text { de se comunicar } \\
\text { e no modo } \\
\text { (modificação): } \\
\text { exposiça de } \\
\text { arte itinerante. }\end{array}$ & $\begin{array}{l}\text { Massificação } \\
\text { pela quantidade } \\
\text { de cidades que } \\
\text { receberam a } \\
\text { exposiçãa }\end{array}$ & $\begin{array}{l}\text { Diferenciação } \\
\text { na forma de } \\
\text { comunicação. }\end{array}$ & $\begin{array}{l}\text { Salto: passagem } \\
\text { brusca na } \\
\text { comunicação } \\
\text { e transposição } \\
\text { de gênero. }\end{array}$ & $\begin{array}{l}\text { Evolução: } \\
\text { acréscimo na } \\
\text { formatação } \\
\text { e ruptura } \\
\text { pelo corte } \\
\text { repentino na } \\
\text { forma de se } \\
\text { comunicar } \\
\text { (exposição } \\
\text { itinerante). }\end{array}$ & $\begin{array}{l}\text { Mudança } \\
\text { no } \\
\text { processo: } \\
\text { ação do } \\
\text { sujeito. }\end{array}$ & |-- \\
\hline 7 & $\begin{array}{l}\text { Criação relativa: } \\
\text { Exposição } 4 \text { - } \\
\text { Zoom latino- } \\
\text { americano - } \\
\text { Coleção Femsa } \\
\text { (Campinas, SP: } \\
\text { CPFL Cultura) }\end{array}$ & $\begin{array}{l}\text { Mudança } \\
\text { na forma } \\
\text { (transformação) } \\
\text { de se comunicar } \\
\text { e no modo } \\
\text { (modificação): } \\
\text { exposiça } \\
\text { de arte. }\end{array}$ & $\begin{array}{l}\text { Massificação } \\
\text { pela quantidade } \\
\text { de cidades que } \\
\text { receberam a } \\
\text { exposição. }\end{array}$ & $\begin{array}{l}\text { Diferenciação } \\
\text { na forma de } \\
\text { comunicação } \\
\text { - exposição } \\
\text { especial de } \\
\text { pintores } \\
\text { latino- } \\
\text { americanos. }\end{array}$ & $\begin{array}{l}\text { Salto: passagem } \\
\text { brusca na } \\
\text { comunicação } \\
\text { e transposição } \\
\text { de gênero. }\end{array}$ & $\begin{array}{l}\text { Evolução: } \\
\text { acréscimo na } \\
\text { formatação } \\
\text { e ruptura } \\
\text { pelo corte } \\
\text { repentino na } \\
\text { forma de se } \\
\text { comunicar } \\
\text { (exposição } \\
\text { especial). }\end{array}$ & $\begin{array}{l}\text { Mudança } \\
\text { no } \\
\text { processo: } \\
\text { ação do } \\
\text { sujeito. }\end{array}$ & --- \\
\hline Totais & 07 & 07 & 07 & 07 & 07 & 07 & 07 & 02 \\
\hline
\end{tabular}

Fonte: Dados da pesquisa dos autores.

A primeira observação é que 20\% do conjunto de ações e eventos criados e implementados pela CPFL está inserido nas categorias de inovação adotadas. Relevante ressaltar que a maioria das ações está inserida nas oito categorias preconizadas por Rossetti (2013), somando-se cinco processos de comunicação de memória pertinentes a todas as categorias de inovação. Cinco eventos referentes às exposições não estão categorizados como produtos novos ou inovados, na categoria inovação passiva.

Respeitando-se a sequência de categorias utilizadas, pode-se inferir que nas sete ações analisadas houve criatividade, mas não invenção, características da categoria substancial. Seis das sete análises indicam que os gestores da comunicação se valeram de situações e/ou processos comunicacionais já existentes em seis momentos (criação relativa) e, em uma das ações, criou-se algo totalmente inédito (criação absoluta), que foi a negociação junto à Pinacoteca do Estado para exposição de suas obras. No caso das outras exposições, as mesmas, por apresentarem o caráter de temporárias, já tinham a característica de serem itinerantes.

Em relação à categoria qualitativa, as análises evidenciaram que alteração, mudança na forma (seis incidências) e, concomitantemente, no modo de se comunicar a memória (sete incidências) estiveram presentes no "Projeto CPFL 100 anos", com destaque para alteração na comunicação em dois eventos: Esquadrilha da Fumaça e a corrida noturna.

Na categoria quantitativa, situações de multiplicação, a massificação do processo comunicacional (cinco incidências) é visível em todas as exposições e, no caso da corrida e das apresentações da Esquadrilha da Fumaça, a multiplicidade se deu pela quantidade de apresentações que se sucederam à primeira. 
Em termos de inovação relativa, na qual a diferenciação e a diversificação são as essências de análise, levantou-se que a diferenciação esteve em todos os produtos e eventos gerados. Na categoria de inovação espacial, a análise dos dados apresentou, simultaneamente, sete momentos de salto e sete momentos de transposição, nos quais a comunicação esteve em cenários em que houve mudança no sentido de deslocamento, transição ou passagem: salto de um lugar a outro e transposição a outro lugar diferente da origem.

Situações inovadoras foram identificadas na categoria temporal. De forma simultânea, as atividades apresentaram evolução e ruptura, em todos os casos. Houve mudança no sentido da geração e do aumento da comunicação, como acontece na evolução, que implica continuidade e acréscimo. Também se visualizou mudança por meio do corte repentino com o estado anterior e o surgimento descontínuo de um novo estado, que caracteriza ruptura, acontecida em todas as exposições e nos demais produtos e eventos (Rossetti, 2013).

As ações do sujeito comunicador estão previstas na categoria de inovação ativa. Os agentes da comunicação atuaram em todos os casos, gerando mudanças no processo em si. Na categoria inovação passiva, na qual o objeto é submetido e passa a absorver o efeito da mudança, foram observadas duas situações: Esquadrilha da Fumaça e corrida noturna.

\section{CONSIDERAÇÕES FINAIS}

0 conjunto comunicacional do "Projeto CPFL 100 anos" teve um componente diferencial em relação a outros projetos pela multiplicidade de linguagens utilizadas. Por meio de linguagens plurais, os produtos apresentaram ações e tecnologias diferenciadas com relativo desenvolvimento e produção de novos formatos, novos processos e ações comunicacionais inovadoras, mesmo quando produziam ações tradicionais da expressão da memória institucional. 0 detalhamento da análise do projeto de comunicação, com vistas à tipificação das inovações presentes nas categorias utilizadas, apresentou os principais vetores da inovação na comunicação da memória da CPFL.

Houve maior incidência, num total de sete ocorrências, nas tipificações de modificação no processo, diferenciação, transposição, salto, evolução e ruptura, bem como forte presença da ação do sujeito inovador da comunicação. Transformações também estão presentes nas ações caracterizadas como inovação qualitativa. A análise categorial permitiu distinções na manifestação de inovação nas diferentes categorias. Assim, sete iniciativas inovadoras, do conjunto de trinta e quatro, revelaram um potencial de inovação de vinte por cento das ações situadas nas oito categorias de Rossetti (2013).

A criatividade foi uma constante, em detrimento da invenção, na categoria substancial. Seis situações demonstraram a existência de alteração e mudança na forma de se comunicar e sete ocorrências de modificação no processo comunicativo. Pela multiplicação dos produtos gerados, a categoria quantitativa foi destaque pela multiplicidade de linguagens utilizadas e na quantidade de produtos. A diferenciação nos produtos especiais os inseriu na categoria de inovação relativa. A inovação espacial foi notada por meio da existência de sete momentos de salto e sete momentos de transposição, bem como verificou-se situações inovadoras na categoria temporal.

Agentes da comunicação atuaram em todos os casos, gerando mudanças nos processos comunicacionais. A inovação passiva, em que o objeto da comunicação absorve o efeito da mudança, esteve visível na Esquadrilha da Fumaça e na corrida noturna. 
Como resultado da pesquisa, considera-se que o "Projeto CPFL 100 anos" inovou relativamente, uma vez que promoveu extensa ação de comunicação da memória institucional. Essa amplitude relativa de inovação teve em seu conjunto a decisão da empresa em contemplar, no geral, ações tradicionais da memória institucional, mas ao mesmo tempo, promovendo aproximadamente um quinto das ações numa perspectiva inovadora de criação relativa, de modificação de práticas anteriores e de massificação na amplitude do público atingido. Assim, tais ações da CPFL inovaram relativamente, pois desenvolveram e aplicaram diferenciação das ações e dos produtos comunicacionais, fazendo com que várias ações e vários produtos tenham acontecido em diversos espaços, gerando produtos que evidenciaram aprimoramento na forma de se comunicar (evolução).

Constatou-se que a empresa CPFL atuou como agente inovador na comunicação institucional por meio da sua memória. Acredita-se que a oportunidade de ser diferente na forma como a organização se comunica com seus públicos possibilita criar uma aproximação com seus colaboradores, permitindo-lhes suas manifestações, suas expressões do sentido de pertencimento e suas possibilidades de engajamento.

A proposta de identificar uma ação estruturada de comunicação de memória empresarial e de trazer à tona tipos diversos de inovação foi um desafio que ainda carece de mais aprofundamento nessa extensa variedade de elementos que se imbricam e que dão forma à pesquisa em comunicação organizacional.

\section{REFERENNCIAS}

BARDIN, Laurence. Análise de conteúdo. Trad. de Luís Antero Reto e Augusto Pinheiro. São Paulo: Edições 70, 2011.

CPFL - Companhia Paulista de Força e Luz. Relatório anual - 2012. Disponível em: <http://www.cpfl.com.br/institucional/ relatorio-anual/Documents/ra-cpfl-2012.pdf>. Acesso em: 05 jul. 2016.

Relatório anual - 2014. Disponível em: <http://www.cpfl.com.br/institucional/ relatorio-anual/Paginas/default. aspx>. Acesso em: 05 jul. 2016.

D'ALMEIDA, Nicole. Memória organizacional: narrativa de uma experiência bem-sucedida ao longo do tempo. Organicom Revista Brasileira de Comunicação Organizacional e Relações Públicas, a.11, n. 20, p. 148-156, 1. sem. 2014.

NASSAR, Paulo. Relações públicas na construção da responsabilidade histórica e no resgate da memória institucional das organizações. 2. ed. São Caetano do Sul, SP: Difusão, 2008.

(org.). Prêmio Aberje 2013: reconhecimento que gera valor. São Paulo: Aberje, 2014.

ROSSETTI, Regina. Categorias de inovação para os estudos em comunicação. Comunicação \& Inovação-Revista do Programa de Pós-graduação em Comunicação da USCS, São Caetano do Sul, v. 14, n. 27, p. 63-72, jul.-dez. 2013. Disponível em: <http:// seer.uscs.edu.br/index.php/revista_comunicação_inovacao/article/view/2262>. Acesso em: 30 jun. 2016.

Artigo recebido em 26.04.2016 e aprovado em 27.05.2016. 